\title{
Conferências de Consenso: a experiência chilena
}

\author{
Consensus conferences: the Chilean experience
}

\author{
Alberto Pellegrini Filho \\ Coordenador da Unidade de Promoção \\ e Desenvolvimento da Pesquisa da \\ Organização Pan-americana da Saúde \\ (OPAS) entre 1989 e 2004. \\ pellecris@uol.com.br
}

\begin{abstract}
A primeira Conferência de Consenso Cidadão realizada no Chile aconteceu entre 22 e 24 de novembro de 2003, em Santiago, fruto de iniciativa da Organização Panamericana de Saúde (OPAS). Buscando fortalecer na América Latina e no Caribe a tendência atual de favorecimento à participação da sociedade na discussão e avaliação de temas científicos e tecnológicos, a OPAS decidiu apoiar a realização de conferências de consenso na região. ${ }^{1}$

A escolha desse mecanismo se deu pelo fato de estarmos em busca de um método adequado para discussões de assuntos relacionados à ciência e à tecnologia que permitisse um debate simétrico entre especialistas e não-especialistas e que contribuísse para a elaboração de políticas públicas, através de documentos elaborados com base no consenso dos participantes. Esse método também deveria ser deliberativo. Entre os mecanismos de participação pública mais difundidos, as conferências de consenso eram as que melhor preenchiam esses quesitos.

O Chile foi escolhido para sediar essa experiência por mostrar um ambiente político favorável à realização de uma atividade participativa nos moldes das conferências de consenso. Depois de 17 anos de ditadura, a sociedade chilena como um todo tem se comprometido com a consolidação do processo de redemocratização do país. Nesse contexto, o Congresso Nacional vem buscando fortalecer a democracia representativa. Por sua vez, o Conselho Nacional de Ciência e Tecnologia (Conicyt), vinculado ao governo chileno, abre-se cada vez mais para a sociedade e tem estimulado a participação pública na definição das agendas de pesquisa. E o Ministério da Saúde vem estimulando e promovendo a participação da sociedade em questões relativas à saúde.
\end{abstract}

\footnotetext{
${ }^{1}$ Para informações mais detalhadas sobre essa experiência, ver: Pellegrini Filho, Alberto; Zurita, Laura. “Primera Conferencia de Consenso Ciudadano en Chile sobre el tema: El manejo de mi ficha clínica de salud - evaluación preliminar". Revista Panamericana de Salud Pública/Pan American Journal of Public Health, v. 15, n. 5, p.351-7, 2004.
} 
A primeira Conferência de Consenso Cidadão do Chile adaptou à realidade nacional as metodologias das conferências de consenso da Dinamarca, país com maior tradição na realização desse tipo de evento. Um representante do Conselho Dinamarquês de Tecnologia, que vem promovendo essas conferências desde 1987, foi ao Chile e acompanhou todo o processo, que durou cerca de seis meses.

É importante destacar que as adaptações respeitaram os princípios básicos de uma conferência de consenso: ausência de qualquer tipo de descriminação no processo de seleção dos cidadãos participantes, transparência e neutralidade no processo e equilíbrio de informações fornecidas, entre outros.

Para a experiência do Chile, em vez de mantermos o nome "conferência de consenso", preferimos denominá-la "conferência de consenso cidadão", obedecendo a um desejo nosso de destacar por igual a importância do consenso e da participação dos cidadãos.

Em uma conferência de consenso, há um gerente de projeto e um conselho diretor responsável pela coordenação e organização de todo o evento. Juntos, decidem o tema geral, aprovam a composição do grupo de cidadãos, asseguram-se de que o material introdutório é adequado e imparcial, decidem sobre a composição final do grupo de especialistas e aprovam o programa da conferência.

O conselho diretor é composto normalmente por três a cinco pessoas, escolhidas pelo gerente do projeto e pela instituição que promove a conferência. Na Dinamarca, o Conselho Dinamarquês de Tecnologia é quem faz essa seleção. No caso do Chile, o Ministério da Saúde, o Conselho Nacional de Ciência e Tecnologia (Conicyt) e o Congresso Nacional deram o apoio político e financeiro para a organização da conferência. O conselho diretor foi constituído por representantes dessas instituições e por um representante da Organização Pan-americana de Saúde (OPAS). Essa composição foi bastante positiva na medida em que criou um espaço de colaboração entre as três instituições e permitiu uma ampla divulgação junto à "clientela" dessas diversas instituições - profissionais da área de saúde, pesquisadores, responsáveis pela elaboração de políticas públicas, cidadãos...

A escolha do tema diferiu bastante do processo tradicional. Geralmente, as conferências de consenso são convocadas quando um determinado tema científico ou tecnológico causa polêmica, dúvidas e temores na sociedade. Elas podem ser realizadas também quando determinada instituição deseja explorar a opinião pública sobre algum assunto. O ideal é que ele seja bem específico, não muito abstrato, controverso e de amplo interesse público. No Chile, o objetivo de se realizar uma conferência de consenso era, sobretudo, testar esse novo mecanismo de participação pública. O tema “O manejo da minha ficha de saúde" foi escolhido pelo conselho diretor porque tramitava naquele momento no Congresso Nacional um projeto sobre os direitos e deveres dos pacientes. A proposta era explorar as implicações legislativas, éticas, administrativas e médicas do tema a fim de melhorar o gerenciamento e o atendimento na área de saúde.

A escolha do grupo de cidadãos também deve respeitar alguns critérios importantes para manter a integridade do processo e validar seu resultado. O grupo é formado por voluntários de todo o país interessados no assunto. Eles são informados sobre a realização da conferência por meio de anúncios divulgados em diferentes lugares e diversas mídias. De todos os candidatos inscritos, são selecionadas de 10 a 16 pessoas que, segundo critérios de idade, sexo, nível de educação, ocupação e habitação, entre outros, devem representar um amplo leque de opiniões e atitudes. É muito importante que nenhum 
dos participantes seja especialista no tema em discussão ou membro de algum grupo de interesse na área. O grupo tem várias tarefas, que incluem adquirir conhecimento básico no assunto, formular questões-chave, analisar a informação recebida durante a conferência e escrever o documento final.

A maioria desses critérios foi respeitada na experiência chilena. Foram escolhidos oito homens e oito mulheres, entre quinhentos voluntários - um número surpreendente. Todos receberam transporte, alojamento e refeições durante os finais de semana preparatórios e no final de semana da conferência. Outros critérios, no entanto, tiveram de ser mais flexíveis. Não foi possível, por exemplo, por razões orçamentárias, recrutar voluntários de todo o país. Participaram da conferência habitantes da zona central do Chile - regiões V, VI e XIII (que correspondem a Viña del Mar, Rancagua e Região Metropolitana de Santiago, respectivamente). Mesmo assim, acreditamos que tenha sido possível abarcar uma amostra bem diversificada da população chilena. Outra limitação no recrutamento foi que os voluntários eram todos usuários dos serviços de saúde, já que a divulgação do processo seletivo foi feita, sobretudo, em consultórios médicos, hospitais e postos de saúde. Acreditamos que esse não seja o método de convocação adequado, já que todos os cidadãos deveriam participar e não apenas aqueles afetados pelo problema.

Foi muito difícil escolher o facilitador (moderador), que coordena todo o processo e estabelece uma relação direta com o grupo de cidadãos. É uma escolha muito importante, porque o facilitador é a pessoa que vai assegurar a qualidade do processo de discussão e da construção do consenso entre os participantes. Essa pessoa não deve ter um conhecimento profundo sobre o tema, mas deve ter experiência em comunicação e em trabalho de cooperação entre grupos heterogêneos de pessoas. O Ministério da Saúde sugeriu que seu representante fosse o facilitador, proposta não aceita pelo conselho diretor. Era necessário que o facilitador fosse uma pessoa independente, particularmente na discussão de um tema de saúde. Além da dificuldade de achar alguém com o perfil adequado, o atraso na liberação da verba resultou em atraso na escolha do facilitador. Selecionado um dia antes do primeiro fim de semana preparatório, não teve tempo suficiente para se preparar com o gerente do projeto, o que seria ideal.

Dois ou três meses antes da conferência, como geralmente ocorre, organizamos o primeiro fim de semana preparatório com a participação do grupo de cidadãos, o gerente do projeto e o facilitador.

O objetivo desse primeiro encontro é fazer a apresentação dos membros do grupo de cidadãos, explicar o método, fornecer informação sobre o tema através de uma ou duas palestras, formular a primeira versão das questões-chave e indicar o tipo de especialistas que deverão responder a essas perguntas.

Normalmente, no primeiro fim de semana, os cidadãos fazem uma série de perguntas sobre o processo e sobre o tema e expressam suas expectativas e preocupações relativas a ele. No caso chileno, no entanto, os participantes tinham pouco interesse pelo tema da conferência; o principal atrativo era poder participar de um processo de tomada de decisão. Isso mostra uma grande necessidade de os cidadãos serem ouvidos e terem suas opiniões consideradas, situação que provavelmente se observa em outros países da região. Algumas medidas motivadoras foram tomadas pelo facilitador e pelo gerente de projeto para que os cidadãos concentrassem sua atenção no tema.

Foi interessante notar a dificuldade dos cidadãos em entenderem que estavam ali para representarem a si mesmos, e não a grupos e nem a categorias. A coordenação do evento 
precisou frisar esse aspecto diversas vezes. Ao longo do processo, no entanto, os cidadãos foram tomando consciência disso e entendendo melhor seu papel.

Cerca de um mês antes da conferência, organizou-se um segundo fim de semana preparatório. Esse segundo encontro visa atender às solicitações dos cidadãos feitas no primeiro fim de semana e finalizar a formulação das questões-chave. Embora tenham sido realizadas diversas palestras e formuladas as perguntas a serem respondidas pelos especialistas, o encontro não teve muito sucesso por causa de problemas internos no grupo. Os cidadãos também mostraram certa dificuldade em redigir as perguntas, que não ficaram tão claras, precisas e bem estruturadas quanto deveriam.

A conferência de consenso, segundo o modelo dinamarquês, tem três dias de duração. No primeiro, os especialistas convidados, entre 10 e 15 pessoas, fazem apresentações curtas tentando responder às perguntas formuladas pelo grupo de cidadãos. Após cada apresentação, os participantes têm a oportunidade de tirar as dúvidas com os especialistas. Na noite do primeiro dia, os cidadãos se encontram e decidem que aspectos ainda precisam ser mais bem explicados. Uma nova bateria de perguntas então é feita para os especialistas responderem no segundo dia.

A conferência chilena diferiu um pouco do modelo dinamarquês. Por causa das limitações no orçamento, as discussões do primeiro dia ficaram restritas ao período da manhã. Diferentemente do que ocorre na Dinamarca, onde as perguntas são divididas de acordo com a especialidade de cada expert, no Chile, todas as perguntas foram entregues a todos os especialistas. Embora cada um devesse escolher entre as perguntas relacionadas a suas especialidades, isto acabou resultando em apresentações mais gerais e que não respondiam, muitas vezes, às perguntas feitas pelo grupo.

Na tarde e na noite do segundo dia, o grupo de cidadãos prepara o documento final, usando as questões-chave como base de argumentos e recomendações. Esse processo costuma tomar bastante tempo e deve contar com a contribuição de todos. A experiência chilena seguiu os mesmos procedimentos. No entanto, como a redação do documento durou quase a noite toda, alguns participantes foram dormir, delegando aos demais colegas a responsabilidade de terminar o documento, o que dificilmente ocorre na Dinamarca.

O terceiro dia é dedicado à apresentação do documento final. Um membro do grupo dos cidadãos lê o documento em voz alta. Nessa etapa, os especialistas têm a oportunidade de corrigir qualquer erro técnico ou mal-entendido, mas não podem, de forma alguma, alterar o seu conteúdo. Ao final da apresentação, os especialistas e a platéia presentes podem formular perguntas e discutir as conclusões do trabalho com o grupo de cidadãos. Geralmente, quando a parte oficial da programação é concluída, a mídia é recebida em uma entrevista coletiva com os participantes da conferência: cidadãos, especialistas e organizadores.

O ministro da Saúde e vários congressistas, incluindo o presidente do Congresso, estiveram presentes na sessão final da conferência no Chile. Após a apresentação do documento final, embora tenham feito apenas referências parciais ao documento, autoridades presentes deram ênfase à importância do processo da conferência. Como a conferência em si e suas metodologias eram novidade na vida política do país, esse comportamento era perfeitamente justificável.

Apesar dos pequenos problemas e contrapontos mencionados, acreditamos que a Conferência de Consenso Cidadão que realizamos no Chile tenha alcançado seus objetivos. 
Ela serviu como um excelente projeto-piloto para a organização de conferências similares em outros países latino-americanos. A participação do público durante a conferência foi bastante ativa e o diálogo entre os cidadãos e especialistas deu-se de forma bastante fluida.

A manifestação espontânea de um dos membros do grupo de cidadãos durante a avaliação expressa muito bem o espírito que prevaleceu na conferência: "Aqui ninguém foi mais importante que o outro". As conferências de consenso dão poder àqueles que normalmente não o têm.

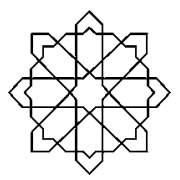




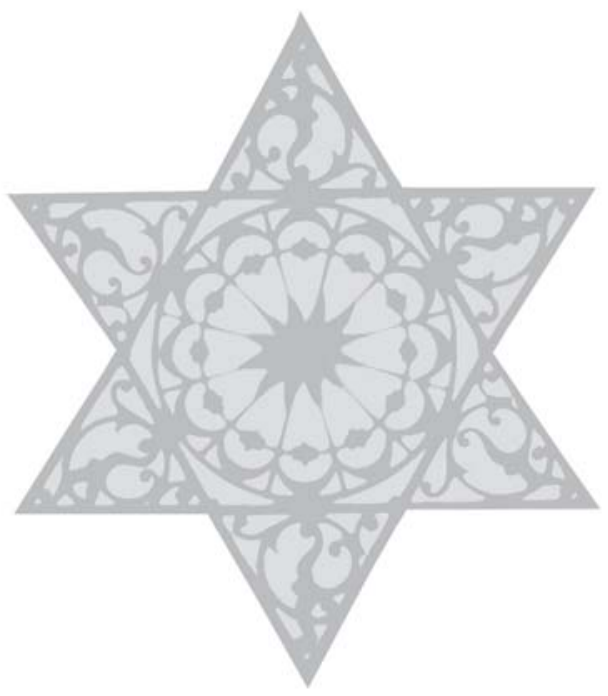

